\title{
Surgical treatment of aortic coarctation in infants younger than three months: 1985 to 1990
}

\author{
Success of extended end-to-end arch aortoplasty
}

There remains controversy regarding the appropriate surgical treatment of coarctation of the aorta in infants. In 1985 we introduced the extended end-to-end repair into our practice and now wish to present a review of our recent experience. One hundred fifty-one infants younger than 3 months of age underwent repair of coarctation between 1985 and 1990 . In $25 \%$ and $33 \%$ of the patients, there was hypoplasia of the isthmus and of the transverse arch, respectively. Surgical procedures were as follows: subclavian flap angioplasty in 15 patients, resection with a traditional end-to-end anastomosis in 43 , and resection with an extended end-to-end anastomosis into the arch in 77 . In 30 patients, the extension was proximal to the origin of the left carotid artery (radically extended end-to-end anastomosis). Other procedures were used in 16 patients. Mortality (13 early and 12 late deaths) was related on multivariate analysis to the presence of an associated major heart defect, preoperative resuscitation, and direct postoperative gradient over the arch. This immediate postoperative gradient was significantly lower after both extended and radically extended end-to-end anastomosis if there was a hypoplastic isthmus, and after radically extended end-to-end anastomosis if the transverse arch was hypoplastic. Actuarial freedom from recoarctation at 4 years was $57 \%$ (confidence limits $28 \%$ to $\mathbf{7 8} \%$ ) after subclavian flap angioplasty, $77 \%$ (confidence limits $60 \%$ to $87 \%$ ) after end-to-end anastomosis, $83 \%$ (confidence limits $66 \%$ to $92 \%$ ) after extended end-to-end anastomosis and 96\% (confidence limits $77 \%$ to $100 \%$ ) after radically extended end-to-end anastomosis. We conclude that the extended end-to-end anastomosis and radical end-to-end anastomosis appear to offer the best prognosis for all infants with coarctation. The technique can be applied successfully to almost all types of arch anomalies. (J ThORAC CARDIOvasC SuRg 1994;107:74-86)

L. W. E. van Heurn, MD (by invitation), C. M. Wong, MD (by invitation),

D. J. Spiegelhalter, $\mathrm{MD}^{\mathrm{a}}$ (by invitation), K. Sorensen, $\mathrm{MD}^{\mathrm{b}}$ (by invitation),

M. R. de Leval, MD (by invitation), J. Stark, MD, and M. J. Elliott, MD (by invitation),

London and Cambridge, England

From the Medical Research Council, Biostatistics Unit, Cambridge, ${ }^{a}$ and the Hospital for Sick Children, Great Ormond Street, London, England.

Read at the Seventy-second Annual Meeting of The American Association for Thoracic Surgery, Los Angeles, Calif., April 26-29, 1992.

Supported by the Clarissa Norman Fund at The Hospital for Sick Children, London, and by the Danish Heart Foundation. ${ }^{b}$

Address for reprints: Martin J. Elliott, MD, FRCS, Cardiac Unit, Hospital for Sick Children, Great Ormond Street, London, WC1N $3 \mathrm{JH}$, England.

Copyright (c) 1994 by Mosby-Year Book, Inc.

$0022-5223 / 94 \$ 1.00+.10 \quad 12 / 6 / 46698$
$\mathrm{O}$ ver the past 30 years, there has been continued improvement in the results of operation in infants for coarctation of the aorta. This has been particularly evident in the case of simple coarctation (without associated intracardiac defects). The surgical treatment of coarctation of the aorta with a hypoplastic arch remains controversial. The mortality and prevalence of residual gradients remain relatively high..$^{1-3} \mathrm{~A}$ variety of surgical techniques for coarctation repair have been described, with subclavian patch angioplasty, resection with end-toend anastomosis, and prosthetic patch angioplasty being 
the most widely reported techniques. ${ }^{4-7}$ Knowledge of the prevalence of residual and recurrent coarctation after each of these techniques is an important factor in the surgeon's choice of technique. We reported ${ }^{8}$ the results of operations for aortic coarctation at our institution from 1976 to 1984 , showing a recoarctation rate of $18.4 \%$. We were not completely satisfied with these results; therefore, after Zannini and associates ${ }^{9}$ and Lansman and associates ${ }^{10}$ described techniques of extended end-to-end anastomosis that were similar to a component of an operation described by Amato, Rheinlander, and Cleveland ${ }^{11}$ in 1977 , we introduced these methods into our practice in 1985.

We subsequently proposed a modification of the technique of Zannini and associates ${ }^{12}$ to cope with more extensive proximal hypoplasia of the aortic arch. This report retrospectively reviews our experience with the various procedures used at our institution from 1985 to 1990.

\section{Patients and methods}

The clinical records of all patients younger than 3 months of age operated on for coarctation of the aorta between January 1985 and December 1990 were studied retrospectively. All patients were followed up as outpatients, but when local followup was not available, detailed questionnaires were sent to the relevant attending cardiologists, or communication was made directly with the patient's family practitioner by telephone. Data were charted on a DBase 4.0 spreadsheet (Ashton-Tate Corporation) for statistical analysis, which was carried out by the methods indicated later.

Definitions. The following definitions were used during the study and are used in this report.

The aortic arch. The aortic arch comprised the transverse arch and isthmus. The transverse arch was defined as lying between the brachiocephalic artery and the left subclavian artery. The isthmus was defined as the part of the arch between the left subclavian artery and the ductus (or ligamentum arteriosus) arteriosus.

Hypoplasia. Hypoplasia was judged to be present if so stated in the contemporary report of the echocardiographic studies or if assessed subjectively by the operating surgeon at the time of operation. These definitions were used because they reflect most accurately the decision-making process used during the course of this study. Prospective echocardiographic or angiographic measurements of the aortic arch segments were not routinely performed. All echocardiograms were performed, however, by experienced cardiologists or echocardiographers. For further comment, see the Discussion section.

Preoperative resuscitation. Preoperative resuscitation was said to have been performed in patients requiring external cardiac massage at any stage before operation, during admission at our institution, in transit, or at the referring hospital.

Recoarctation. At the end of the operation, the pressure distal to the repair of the coarctation was measured directly and recorded, as was the pressure in a right arm artery. The gradient between the two was defined as the immediate postrepair gradient. If, at the time of most recent review, a gradient of less than $20 \mathrm{~mm} \mathrm{Hg}$ was detected and if, in the same child, a gradient of greater than $20 \mathrm{~mm} \mathrm{Hg}$ had been found immediately
Table I. Associated cardiac anomalies (group III)

\begin{tabular}{|c|c|c|}
\hline \multirow{2}{*}{$\frac{\text { Associated lesions }}{\text { Left ventricular outfiow tract obstruction }}$} & \multicolumn{2}{|c|}{$\begin{array}{l}\text { No. of cases } \\
\text { (early deaths/ } \\
\text { late deaths) }\end{array}$} \\
\hline & & 10 \\
\hline Valvular & $2(1 / 0)$ & \\
\hline Valvular and VSD type & $3(0 / 2)$ & \\
\hline Valvular and DORV & $1(1 / 0)$ & \\
\hline Nonvalvular & $1(0 / 0)$ & \\
\hline Nonvalvular and VSD & $3(1 / 0)$ & \\
\hline Atrioventricular septal defect & & 7 \\
\hline AVSD & $5(2 / 1)$ & \\
\hline $\begin{array}{l}\text { AVSD and abnormal pulmonary } \\
\text { venous drainage }\end{array}$ & $1(1 / 0)$ & \\
\hline $\begin{array}{l}\text { AVSD and double outlet } \\
\text { right ventricle }\end{array}$ & $1(1 / 0)$ & \\
\hline Transposition of the great arteries & & 6 \\
\hline Simple & $1(0 / 0)$ & \\
\hline $\begin{array}{l}\text { DORV with anterior aorta } \\
\text { (transposition of the great arteries } \\
\text { physiologic features) }\end{array}$ & $4(1 / 2)$ & \\
\hline $\begin{array}{l}\text { DILV with VSD and anterior aorta } \\
\text { from RV }\end{array}$ & $1(0 / 0)$ & \\
\hline Mitral valve abnormalities & & 6 \\
\hline Stenosis & $3(1 / 1)$ & \\
\hline Stenosis with VSD & $2(0 / 0)$ & \\
\hline Parachute valve & $1(0 / 1)$ & \\
\hline Double-outlet right ventricle & $(0 / 0)$ & 2 \\
\hline $\begin{array}{l}\text { Dextrocardia and hypoplastic } \\
\text { left ventricle }\end{array}$ & $(1 / 0)$ & 1 \\
\hline Pulmonary valve stenosis & $(0 / 0)$ & 1 \\
\hline PAPVD & $(1 / 0)$ & 1 \\
\hline Aortopulmonary window & $(0 / 0)$ & 1 \\
\hline Total & & $\overline{35}$ \\
\hline
\end{tabular}

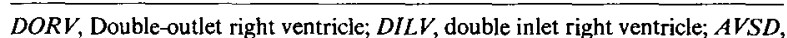
complete atrioventricular septal defect; $P A P V D$, partial anomalous pulmonary venous drainage.

after repair, then this was defined as residual coarctation. This is an important point because some children will have a gradient of greater than $20 \mathrm{~mm} \mathrm{Hg}$ immediately after repair, but this gradient may resolve during follow-up if there is growth of the hypoplastic aortic arch. ${ }^{13}$ Recurrent coarctation was said to have occurred if, at last review, either a gradient of greater than $20 \mathrm{~mm} \mathrm{Hg}$ (undetected at the time of the repair) was found or an increase in gradient of greater than $20 \mathrm{~mm} \mathrm{Hg}$ occurred in a patient with a gradient of similar degree immediately after the repair; thus, an immediate postoperative gradient of greater than $20 \mathrm{~mm} \mathrm{Hg}$ can indicate eventual recurrent coarctation. Routine echocardiographic studies, including two-dimensional echocardiography and Doppler assessment of pressure gradients, were carried out at varying intervals during follow-up. However, if a cardiac murmur, hypertension (defined as systolic and diastolic blood pressure higher than appropriate for age range,,$^{14}$ diminished femoral pulses, or blood pressure gradients between the right arm and legs were present, then further echocardiographic studies were carried out. If no abnormal signs were detected at the last (most recent) follow-up, then the patient was considered to be free of recoarctation.

Early death. Early death was defined as death within 30 days of operation or death before discharge from the hospital. 


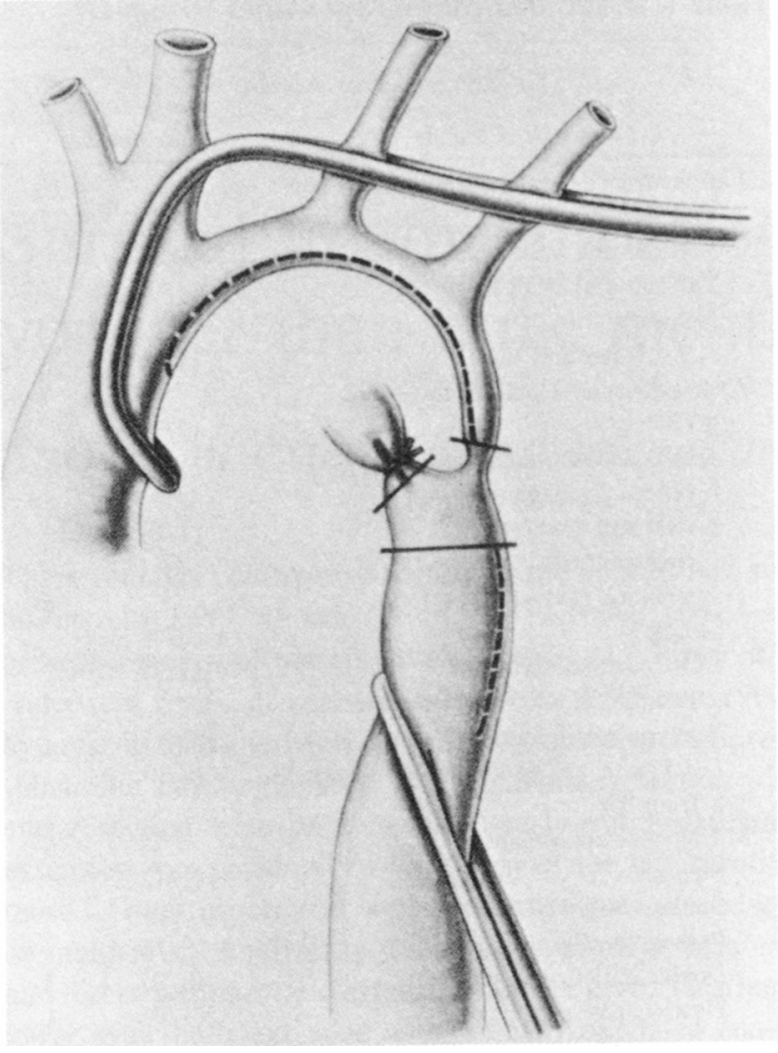

Fig. 1. Drawing of positioning of coarctation clamps during radically extended end-to-end repair of aortic arch. For less radical extension of repair, innominate artery is excluded from proximal clamp. Reprinted with permission from the Society of Thoracic Surgeons (The Annals of Thoracic Surgery 1987; 44:321-3).

Patient population. Between January 1985 and December 1990,151 consecutive infants younger than 3 months of age ( 95 boys and 56 girls; median age 12 days, range 2 to 90 days) underwent surgical repair of aortic coarctation.

The median weight was $3.3 \mathrm{~kg}$. Seventy-two children (47.7\%) had simple coarctation (group I), 44 (29.1\%) had an additional ventricular septal defect (VSD) (group II), and 35 (23.2\%) had additional complex heart disease (group III). Table I shows the associated defects in these patients. A patent ductus arteriosus was present in 107 patients (70.8\%). Sixty-four children $(42.4 \%)$ had an aortic arch of normal size (group A). Aortic hypoplasia was present in 87 patients $(58 \%), 37(24.5 \%)$ with a hypoplastic isthmus (group B) and $50(33.1 \%$ ) with hypoplasia of the transverse arch (group C). Details of the distribution of arch anatomy by group are shown in Table II. All infants had associated symptoms. Nineteen $(12.6 \%)$ had been resuscitated before the operation, $48(31.8 \%)$ received ventilatory support, and $15(9.9 \%)$ had impaired renal function (creatinine level higher than $100 \mu \mathrm{mol} / \mathrm{L}$ ), 1 of whom required preoperative peritoneal dialysis. A preoperative prostaglandin $E_{1}$ infusion was given in 64 patients $(42.4 \%)$.

Operative technique. Fifteen patients $(9.9 \%)$ underwent subclavian flap angioplasty, $43(28.5 \%)$ underwent resection
Table II. Distribution of arch anatomy in 151 patients with simple coarctation (group I), coarctation with additional VSD (group II), and coarctation with associated major heart defect (group III)

\begin{tabular}{|c|c|c|c|}
\hline & $\begin{array}{c}\text { Normal } \\
\text { arch }\end{array}$ & $\begin{array}{l}\text { Hypoplastic } \\
\text { isthmus }\end{array}$ & $\begin{array}{c}\text { Hypoplastic } \\
\text { transverse } \\
\text { arch }\end{array}$ \\
\hline Associated defect & No. $(\%)$ & No. $(\%)$ & No. $(\%)$ \\
\hline Simple coarctation & $42(27.9)$ & $14(9.2)$ & $16(10.6)$ \\
\hline Coarctation with VSD & $10(6.6)$ & $17(11.3)$ & $17(11.3)$ \\
\hline $\begin{array}{l}\text { Coarctation with major } \\
\text { heart defect }\end{array}$ & $12 \quad(7.9)$ & $6 \quad(4.0)$ & $17(11.3)$ \\
\hline Total & $64(42.4)$ & $37(24.5)$ & $50(33.1)$ \\
\hline
\end{tabular}

and a traditional end-to-end anastomosis, $3(2 \%)$ underwent a combination of these two procedures, and $1(0.7 \%)$ underwent a carotid flap angioplasty. In 87 patients, an end-to-end anastomosis was extended: 47 anastomoses $(31.1 \%)$ extended into the undersurface of the arch, $4(2.6 \%)$ extended into the subclavian artery, and $6(4 \%)$ extended into both. In 30 patients $(19.9 \%)$, the incision was radically extended into the arch, and the arch was further defined as extending proximally to the origin of the left carotid artery.

Details of extended and radically extended aortoplasties. Blood pressure in the extended and radically extended procedures is monitored by means of a catheter in a right arm artery. A pulse oximeter is positioned on the left hand to determine the presence of pulsation. The superior aortic crossclamp is positioned as proximally as possible. The position is evaluated by the quality of arterial pulse trace in the right arm. If the arterial pulse trace is very dense, then the crossclamp is moved slightly distally. In both the extended and radically extended operations, the aorta was approached in the usual way via a left thoracotomy. The tissue overlying the aorta was incised with diathermy, and the aorta and its branches were mobilized largely with diathermy and blunt dissection.

The mobilization is a very important part of the extended arch aortoplasties and warrants more detailed description. The descending aorta and its intercostal branches are mobilized to about two thirds of the way to the diaphragm such that the aorta can be moved freely up and down. Intercostal vessels are rarely divided. Temporary loop ligatures can be used to control the intercostal vessels if required. The subclavian artery should be mobilized to its first division. A large lymphatic vessel, sometimes seen crossing the subclavian artery, should be ligated. Tongues of tissue are divided between the subclavian artery and left carotid artery and between the left carotid artery and innominate artery. Blunt dissection can then continue around the posterior and medial parts of the arch until the ascending aorta and opposite side of the innominate artery are clearly visible.

Once the mobilization is complete, the ductus can be ligated. We have found that the operation is greatly facilitated by the use of specially designed clamps (Elliott Coarctation clamps Nos. 30/9050 and 30/9051; Codman \& Shurtleff, Inc., Randolph, Mass.). These clamps are designed to grasp half the carotid and subclavian arteries and a small portion of the innominate and ascending aorta in the same jaws, with the handles deviated well away from the surgeon's field of view (Fig. 1). 
The coarctation can then be resected and the duct divided. It is important to resect only minimal amount of tissue at this stage.

However, once the coarctation has been resected, any tissue that appears to be thickened or ductal in nature should be cut away. Care should be taken to preserve as much of the lateral portion of the isthmus as possible because this acts as an inlay flap into the descending aorta. An incision is then made in the underside of the arch around to a position more proximal than the commencement of hypoplasia of the arch. This incision can be continued to the medial ascending aorta if the proximal clamp position permits. An incision can then be made in the posterolateral aspect of the descending aorta to receive the tongue of isthmic tissue that has been preserved. With the degree of mobilization that has been achieved and the special clamps, the two ends of the aorta can be approximated with ease. The aortic arch is effectively brought down toward the descending aorta, rather than raising the descending aorta toward the aortic arch.

The anastomosis should be begun proximally on the arch with a number of loops inserted both anteriorly and posteriorly before tightening the suture to avoid tearing the aortic tissue. The operation does not take longer than other forms of coarctation repair, and the median crossclamp time in this study was 17 minutes, with a range of 11 to 28 minutes.

Anastomoses were sutured with continuous polypropylene sutures in 107 patients ( $7-0$ in 79 patients, 6-0 in 28 patients), polydioxone sulfate sutures (PDS; Ethicon, Inc., Sommerville, N.J.) in 31 (7-0 in 14,60 in 17), and Maxon sutures (Davis \& Geck, Danbury, Conn.) in 10 patients (7-0 in 6, 6-0 in 4); the suture material was not recorded in three patients.

Additional procedures included ligation of the ductus arteriosus if patent pulmonary artery banding in 37 patients $(24.5 \%)$, VSD closure in 2 patients $(1.3 \%)$, with the coarctation being repaired first from the left side, and transventricular valvotomy via a left thoracotomy in 1 patient. Before the end of the operation, peak systolic pressures were measured simultaneously from the arterial line in the right arm and by direct needle measurement in the descending aorta in $145(96 \%)$ of our 151 patients.

Follow-up. Patients discharged from the hospital were followed up at 3-month intervals per month during the first year after their operation. Thereafter, they were seen at least once a year. Information concerning children not recently reviewed at our institution was obtained from local cardiologists and general practitioners by the primary author (Dr. van Heurn). Follow-up data were obtained during a closed 2-month period (May and June 1991). In one patient (from Kuwait), no recent follow-up could be obtained. This represents a total follow-up of $99.3 \%$.

Statistical analysis. The primary outcome measures investigated were early mortality, total mortality, residual coarctation, and recoarctation at any time after operation. Univariate and multivariate relative risk analysis was carried out for factors measurable at operation with the use of logistic regression for early mortality and residual coarctation and Cox proportional hazard models for total mortality and recoarctation. ${ }^{15,16}$

Risk factors investigated, with their respective categorizations, were as follows: operation type (subclavian flap angioplasty, traditional end-to-end repair, extended end-to-end repair, radically extended end-to-end repair, and other procedures), associated heart defect (simple coarctation, additional VSD, and additional complex heart defect), preoperative resuscitation and resuscitation for cardiac arrest (no, yes), age (12
Table III. Causes of early postoperative death

\begin{tabular}{lc}
\hline \multicolumn{1}{c}{ Cause of death } & No. of patients \\
\hline Operative death (ventricular fibrillation) & 3 \\
Necrotizing enterocolitis & 2 \\
Low cardiac output & 2 \\
Neurologic deficit & 2 \\
Cerebellar hemorrhage and thrombosed SVC & 1 \\
Operative death after recoarctation repair and & 1 \\
$\quad$ VSD repair & 1 \\
Acute liver failure & $\frac{1}{13}$ \\
Blocked endotracheal tube (heart transplantation) & \\
Total & \\
\hline
\end{tabular}

$\overline{S V C, \text { Superior vena cava. }}$

days or younger, older than 12 days, and chosen after preliminary data analysis), weight ( $3.3 \mathrm{~kg}$ or less and more than 3.3 $\mathrm{kg}$ ), hypoplasia (none, isthmus, and transverse arch), suture (absorbable, nonabsorbable, and 7-0 and 6-0), and preoperative treatment with prostaglandin (no, yes).

Operation, associated heart defect, preoperative resuscitation for cardiac arrest, and age were used in all multivariate analyses on the basis of their statistical significance $(p<0.05)$ in at least one of the analyses. Actuarial estimates of freedom from death or recoarctation were calculated with the Kaplan-Meier method. ${ }^{17}$ Proportions are presented with $95 \%$ confidence intervals. Postoperative gradients were compared by means of two-sample $t$ tests.

\section{Results}

Early postoperative death. Thirteen $(8.2 \%$, confidence limits [CL] $4.2 \%$ to $13.2 \%$ ) early deaths occurred. The causes of death are listed in Table III. Eleven patients were observed to have additional major heart defects (group III), and two of the deaths occurred among patients in group I (patients with simple coarctation). One patient, who had the carotid artery flap repair, had a cerebellar hemorrhage, and the other, who had an extended end-to-end repair, had extensive bilateral cerebral damage after a prolonged episode of preoperative resuscitation with asystole. Table IV shows that associated major heart defect $(p<0.001)$ and preoperative resuscitation for cardiac arrest $(p=0.013)$ were the only risk factors that were significant at the 5\% level, with the $95 \%$ confidence intervals for the relative risk include 1 . Table $\mathrm{V}$ details the early mortality for combinations of these factors: no early deaths were recorded in 101 patients with neither associated major heart defect nor resuscitation, whereas the mortality among babies with both factors present was $75 \%$. In multivariate analysis, the effect of these factors was somewhat exaggerated because of a close association between age and resuscitation. Extended and radically extended operations showed a small, nonsignificant improvement.

Immediate postoperative gradient. Table VI shows the mean systolic gradient in the immediate postoperative 
Table IV. Relative risk estimation for early mortality by logistic regression models

\begin{tabular}{|c|c|c|c|c|c|}
\hline & \multirow[b]{2}{*}{ Level } & \multirow[b]{2}{*}{ Rate } & \multicolumn{2}{|c|}{ Odds ratio $(95 \% C L)$} & \multirow[b]{2}{*}{$\mathrm{p}$ Value* } \\
\hline & & & $\begin{array}{c}\text { Univariate } \\
\text { analysis }\end{array}$ & $\begin{array}{c}\text { Multivariate } \\
\text { analysis }\end{array}$ & \\
\hline \multirow[t]{4}{*}{ Surgical procedure } & E-E & $5 / 43$ & 1 & 1 & \\
\hline & SFA & $1 / 15$ & $0.54(0.06-5.06)$ & $0.43(0.03-5.96)$ & \\
\hline & EE-EA/REE-EA & $5 / 77$ & $0.53(0.14-1.94)$ & $0.64(0.11-3.71)$ & \\
\hline & Others & $2 / 15$ & $1.17(0.20-6.77)$ & $4.66(0.44-49.24)$ & \\
\hline \multirow[t]{2}{*}{ Associated defect } & Coarctation \pm VSD & $2 / 116$ & 1 & 1 & \\
\hline & Major defect & $11 / 35$ & $26.13(5.44-125.5)$ & $114.9(9.74-1356)$ & $p<0.001$ \\
\hline \multirow[t]{2}{*}{ Resuscitation } & No & $8 / 131$ & 1 & 1 & \\
\hline & Yes & $5 / 19$ & $5.49(1.58-19.10)$ & $20.07(1.88-214.8)$ & $p=0.013$ \\
\hline \multirow[t]{2}{*}{ Age (days) } & $\geq 13$ & $4 / 75$ & 1 & 1 & \\
\hline & $\leq 12$ & $9 / 76$ & $2.38(0.70-8.11)$ & $4.66(0.81-26.65)$ & \\
\hline \multirow[t]{2}{*}{ Weight (kg) } & $\geq 3.4$ & $4 / 70$ & $2.06(0.61-7.02)$ & & \\
\hline & $\leq 3.3$ & $9 / 81$ & & & \\
\hline \multirow[t]{3}{*}{ Arch anatomy } & Normal & $3 / 64$ & 1 & & \\
\hline & Hypoplasia isthmus & $3 / 37$ & $1.79(0.34-9.38)$ & & \\
\hline & Hypoplasia transverse arch & $7 / 50$ & $3.31(0.81-13.53)$ & & \\
\hline
\end{tabular}

$\overline{E-E}$, Traditional end-to-end anastomosis; $S F A$, subclavian flap angioplasty; $E E-E A$, extended end-to-end anastomosis into the arch; $R E E-E A$, radically extended end-to-end anastomosis.

${ }^{*} p$ was significant if $<0.05$.

Table V. Early mortality ratio

\begin{tabular}{lcccc}
\hline \multirow{2}{*}{$\begin{array}{c}\text { Preoperative } \\
\text { status }\end{array}$} & \multicolumn{4}{c}{ Early deaths/total in group } \\
\cline { 2 - 5 } & $\begin{array}{c}\text { Simple } \\
\text { coarctation }\end{array}$ & $\begin{array}{c}\text { Associated } \\
\text { VSD }\end{array}$ & $\begin{array}{c}\text { Associated } \\
\text { major defect }\end{array}$ & Total \\
\hline Not resuscitated & $0 / 62$ & $0 / 39$ & $8 / 30$ & $8 / 131$ \\
Resuscitated & $\frac{2 / 10}{2 / 72}$ & $\frac{0 / 5}{0 / 44}$ & $\frac{3 / 4}{11 / 34}$ & $\frac{5 / 19}{13 / 150}$ \\
Total & & &
\end{tabular}

period of different procedures in patients with coarctation and a normal arch, additional hypoplastic isthmus, and hypoplastic transverse arch. The choice of operative technique did not influence the immediate postoperative gradient in patients with coarctation without associated hypoplasia (group A). However, the postoperative gradient was significantly lower after either extended or radically extended end-to-end anastomosis if there was a hypoplastic isthmus (group B; $p=<0.005$ ). In infants with a hypoplastic transverse arch (group C), a radically extended end-to-end anastomosis resulted in a significantly lower direct gradient $(p=<0.05)$.

Late death. In 137 hospital survivors with complete follow-up, 12 late deaths occurred $(8.8 \%, \mathrm{CL}=4.1 \%$ to $13.5 \%$ ). In group I, one patient with Pfeiffer's syndrome died of pulmonary infection; in group II, two patients died after VSD repair, one died after cardiac catheterization, and one died of low cardiac output; in group III, six patients died after subsequent cardiac repair and one died of associated cardiac anomaly (parachute mitral valve). The distribution of mortality by diagnosis is shown in
Table I. The actuarial probability of survival in the different groups is shown in Fig. 2.

Total mortality. Table VII shows that in a univariate analysis babies who weighed less were at an increased risk of overall mortality $(p=0.02)$, but this factor did not remain significant after other factors were taken into account. Associated major heart defect $(p<0.001)$ and resuscitation $(p=0.025)$ remained important, and, compared with the traditional end-to-end anastomosis, the extended and radically extended aortoplasty procedures were associated with an apparent reduction in risk, although the possibility that this was due to chance cannot be fully excluded. Fig. 3, which illustrates the mechanism for the increased mortality in group III, shows that patients with a postoperative gradient of more than 20 $\mathrm{mm} \mathrm{Hg}$ had greatly increased mortality. Interestingly, all these patients had undergone additional pulmonary artery banding.

Residual coarctation. Of thirteen patients with an immediate postoperative gradient of more than $20 \mathrm{~mm}$ $\mathrm{Hg}$, eight had a residual gradient at the moment of death, intervention, or last visit (mean direct postoperative gradient $31 \mathrm{~mm} \mathrm{Hg}$ ). In four patients the postoperative gradient had decreased to $20 \mathrm{~mm} \mathrm{Hg}$ or less within 6 months (mean direct postoperative gradient $25 \mathrm{~mm} \mathrm{Hg}$ ). One patient (gradient $25 \mathrm{~mm} \mathrm{Hg}$ ) was lost to follow-up. In the multivariate analysis, the presence of an additional major heart defect was the only significant factor $(p=0.013)$. Although not significant, the best assessment from the data is that the extended and radically extended operations were protective. 


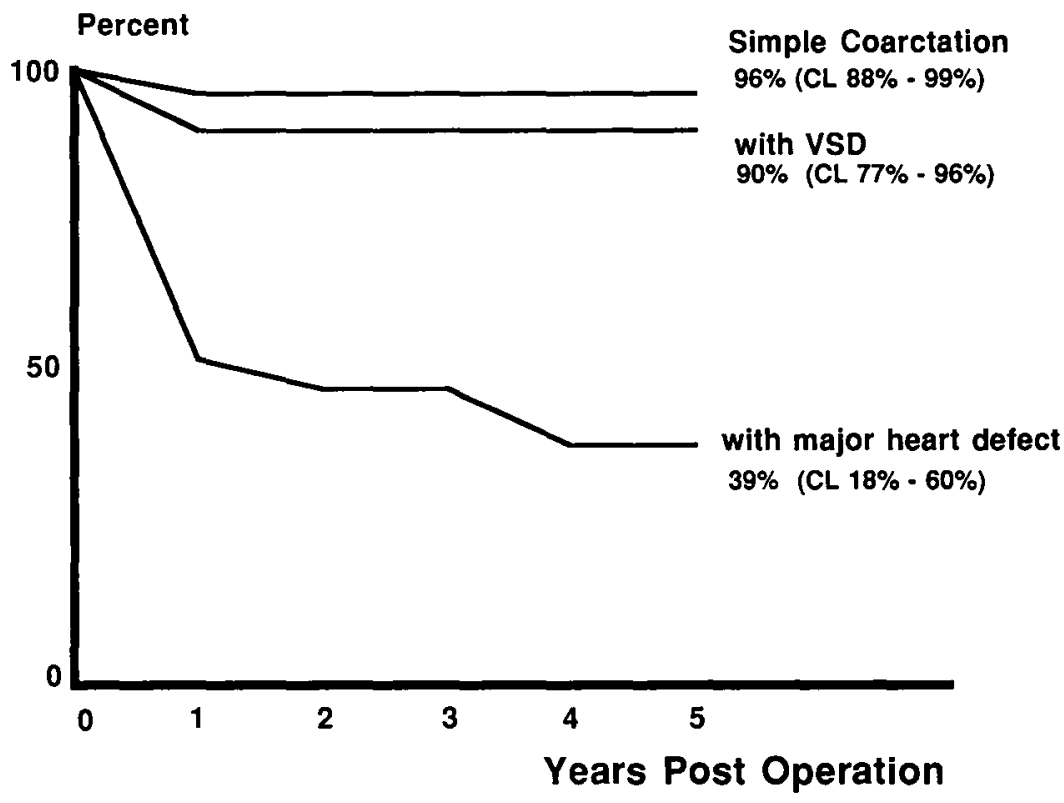

Fig. 2. Actuarial probability of survival of patients with simple coarctation (group I), coarctation with associated VSD (group II), and coarctation with associated major heart defect (group III).

Recurrent coarctation. Recurrent coarctation was identified in 21 patients from 1 day to 53 months after operation, with gradients ranging from 22 to $80 \mathrm{~mm} \mathrm{Hg}$. The only significant risk factor for recurrent coarctation was young age ( $p=0.004$; Fig. 4$)$.

Recoarctation (residual and recurrent combined). As seen in Table VIII, babies younger than 13 days were at increased risk of recoarctation, even when the statistical analysis is adjusted for other factors $(p=0.006)$. Extended and radically extended aortoplasty were associated with a significant $(p=0.025)$ reduction in risk of recoarctation compared with other procedures. The actuarial probability of freedom from recoarctation at 1 year and 4 years was $88 \%(\mathrm{CL}=81 \%$ to $92 \%)$ and $81 \%$ ( $\mathrm{CL}=70 \%$ to $88 \%$ ), respectively, for all patients. The actuarial probabilities of freedom from recoarctation for the four surgical methods used are shown in Fig. 5.

Successful operation for recoarctation was performed in seven patients, and balloon angioplasty in eleven. In six patients, no therapy was necessary. Four patients with recoarctation died: two early in the postoperative period because of necrotizing enterocolitis and neurologic deficit, one after repair of an associated major heart defect, and one after simultaneous VSD closure and recoarctation repair.

Surgical complications. Persistent Horner's syndrome was present in two infants $(1.3 \%)$ who had had aortoplasties that were extended into the subclavian artery. Phrenic nerve paralysis was detected in three
Table VI. Mean direct postoperative gradient (in millimeters of mercury) in patients with coarctation and normal arch, hypoplastic isthmus, and hypoplastic transverse arch by surgical procedure used $(n=145)$

\begin{tabular}{|c|c|c|c|}
\hline & $\begin{array}{c}\text { Normal } \\
\text { arch }\end{array}$ & $\begin{array}{l}\text { Hypoplastic } \\
\text { isthmus }\end{array}$ & $\begin{array}{c}\text { Hypoplastic } \\
\text { transverse arch }\end{array}$ \\
\hline $\begin{array}{c}\text { Surgical } \\
\text { procedure }\end{array}$ & $\begin{array}{c}\text { Gradient } \\
\text { (No. of patients) }\end{array}$ & $\begin{array}{c}\overline{\text { Gradient }} \\
\text { (No. of patients) }\end{array}$ & $\begin{array}{c}\text { Gradient } \\
\text { (No. of patients) }\end{array}$ \\
\hline SFA & $7(7)$ & $14(3)$ & $13(5)$ \\
\hline E-E & $6(24)$ & $15(11)$ & $24(5)$ \\
\hline EE-EA & $6(25)$ & $5(12)$ & $13(10)$ \\
\hline EE-ES & - & $17(4)$ & - \\
\hline EE-ESA & $3(2)$ & $0(1)$ & $15(3)$ \\
\hline REE-EA & $7(3)$ & $5(5)$ & $4(21)$ \\
\hline Other & $0(1)$ & $15(1)$ & $11(2)$ \\
\hline Total & $6(62)$ & $10(37)$ & $\overline{10(46)}$ \\
\hline
\end{tabular}

$E E-E S, \mathrm{E}-\mathrm{E}$ in to the subclavian artery; $E E-E S A, \mathrm{E}-\mathrm{E}$ into the subclavian artery and the arch; See Table IV for abbreviations.

patients $(2 \%)$ who underwent additional pulmonary artery banding; in one it was reversible, but two required surgical plication of the diaphragm. Persistent chylothorax occurred in one patient after subclavian flap angioplasty and required surgical management. Temporary seizures occurred in four children; one (with subclavian flap angioplasty) was resuscitated previously and three (one with extended aortoplasty and two with radically extended aortoplasties) were not. Two children (with 


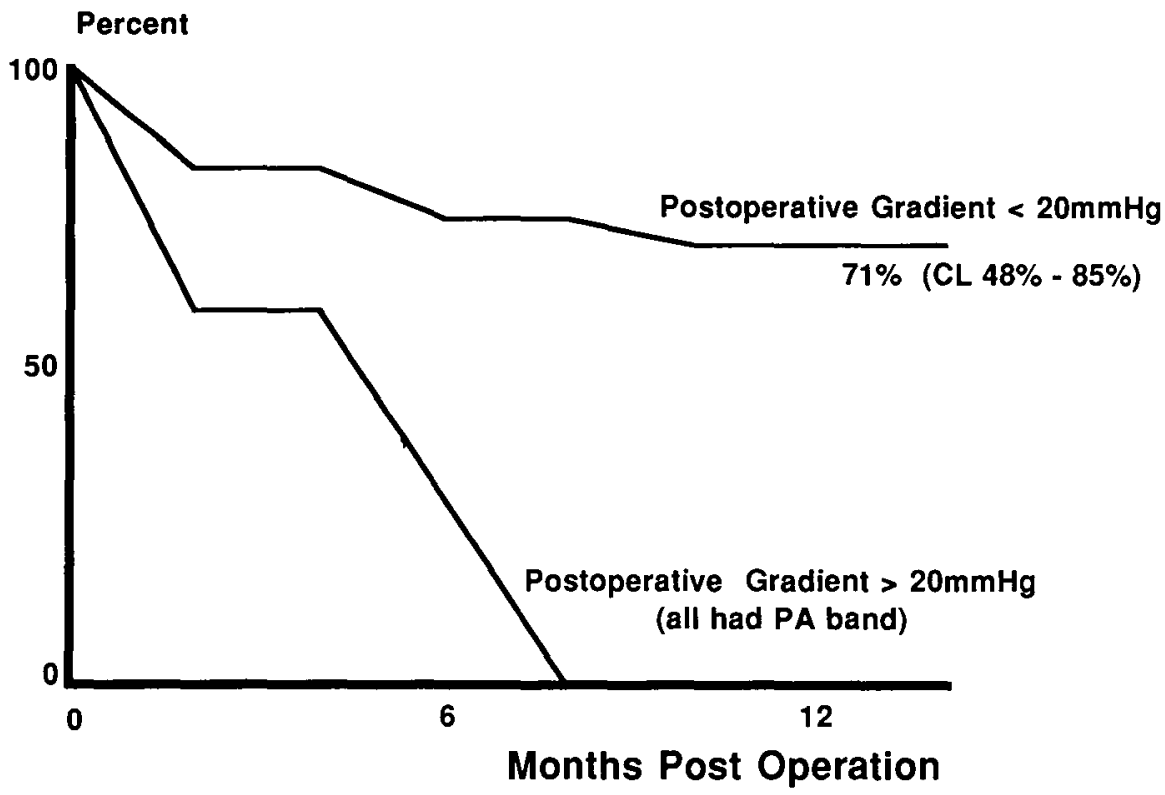

Fig. 3. Actuarial probability of survival of patients with associated heart defect with and without postoperative gradient of $>20 \mathrm{~mm} \mathrm{Hg}$. $P$ A, Pulmonary artery.

Table VII. Hazard ratio estimation for total mortality by Cox proportional hazard models

\begin{tabular}{|c|c|c|c|c|c|}
\hline & \multirow[b]{2}{*}{ Level } & \multirow[b]{2}{*}{ Rate } & \multicolumn{2}{|c|}{ Odds ratio $(95 \% C L)$} & \multirow[b]{2}{*}{$\mathrm{p}$ Value } \\
\hline & & & $\begin{array}{l}\text { Univariate } \\
\text { analysis }\end{array}$ & $\begin{array}{c}\text { Multivariate } \\
\text { analysis }\end{array}$ & \\
\hline \multirow[t]{4}{*}{ Surgical procedure } & E-E & $9 / 44$ & 1 & 1 & \\
\hline & SFA & $4 / 15$ & $1.14(0.35-3.71)$ & $0.79(0.22-2.81)$ & \\
\hline & EE-EA/REE-EA & $9 / 77$ & $0.55(0.22-1.38)$ & $0.54(0.54-1.37)$ & \\
\hline & Others & $3 / 15$ & $0.95(0.26-3.50)$ & $1.60(0.41-6.27)$ & \\
\hline \multirow[t]{2}{*}{ Associated defect } & Coarctation \pm VSD & $7 / 115$ & 1 & 1 & \\
\hline & Major defect & $18 / 35$ & $11.81(4.91-28.38)$ & $15.36(6.12-38.52)$ & $p<0.001$ \\
\hline \multirow[t]{2}{*}{ Resuscitation } & No & $19 / 130$ & 1 & 1 & \\
\hline & Yes & $6 / 19$ & $2.48(0.99-6.22)$ & $3.11(1.15-8.38)$ & $p=0.013$ \\
\hline \multirow[t]{2}{*}{ Age (days) } & $\geq 13$ & $10 / 74$ & 1 & 1 & \\
\hline & $\leq 12$ & $15 / 76$ & $1.46(0.65-3.24)$ & $1.91(0.78-4.71)$ & \\
\hline \multirow[t]{2}{*}{ Weight $(\mathrm{kg})$} & $\geq 3.4$ & $6 / 70$ & $2.98(1.19-7.47)$ & & $p=0.02$ \\
\hline & $\leq 3.3$ & $19 / 80$ & & & \\
\hline \multirow[t]{3}{*}{ Arch anatomy } & Normal & $9 / 64$ & 1 & & \\
\hline & Hypoplasia isthmus & $5 / 37$ & $0.93(0.31-2.77)$ & & \\
\hline & Hypoplasia transverse arch & $11 / 49$ & $1.78(0.74-4.30)$ & & \\
\hline
\end{tabular}

See Table IV for abbreviations.

subclavian flap angioplasty and extended end-to-end aortoplasty), both resuscitated before operation, died with major postoperative neurologic deficit.

Discussion. The data presented in this retrospective review revealed a number of interesting findings. First, the most important risk factors for death after operation for coarctation of the aorta were the presence of an associated major cardiac defect and the requirement for preoperative resuscitation. Both the extended and radically extended end-to-end anastomoses were associated with a slight reduction in the risk of death compared with the traditional end-to-end repair. Thus, operation for simple coarctation or for coarctation associated with an additional VSD appears to carry virtually no risk in current practice. The presence of a hypoplastic aortic arch did not influence outcome adversely.

Second, the prevalence and severity of immediate, directly measured postoperative gradients after repair of 


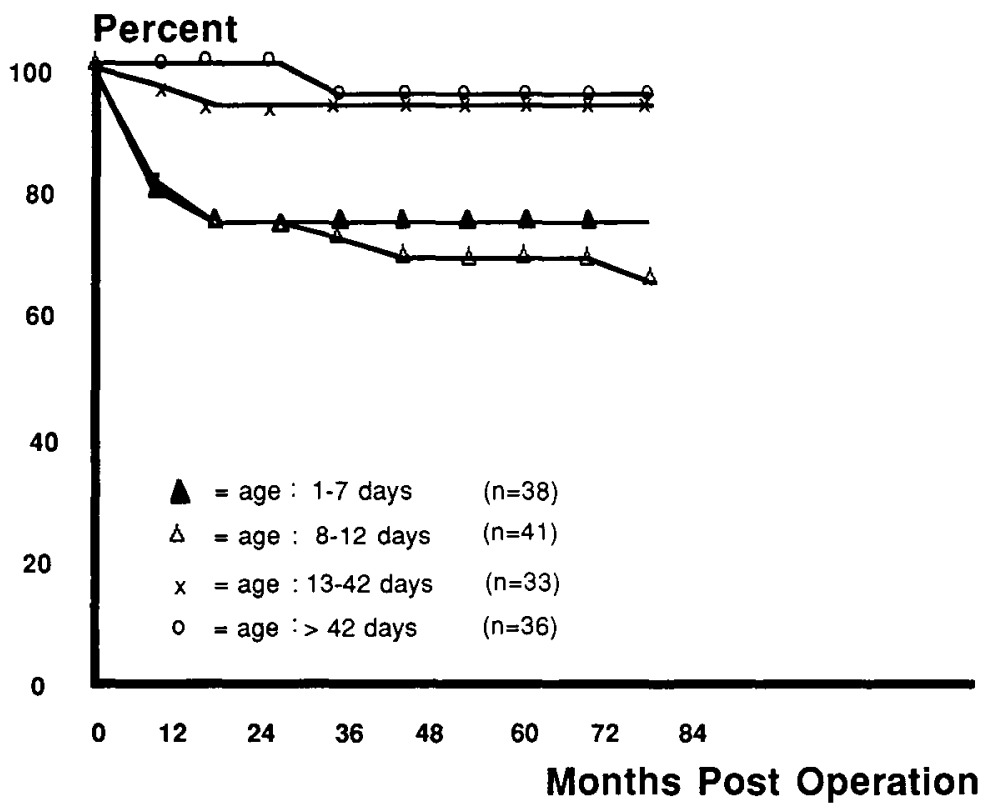

Fig. 4. Actuarial estimation of freedom from recurrent coarctation of patients 1 to 7 days, 8 to 12 days, 13 to 42 days, and $>42$ days of age.

Table VIII. Hazard ratio for recoarctation by Cox proportional hazard models

\begin{tabular}{|c|c|c|c|c|c|}
\hline & \multirow[b]{2}{*}{ Level } & \multirow[b]{2}{*}{ Rate } & \multicolumn{2}{|c|}{ Odds ratio $(95 \% C L)$} & \multirow[b]{2}{*}{ p Value } \\
\hline & & & $\begin{array}{l}\text { Univariate } \\
\text { analysis }\end{array}$ & $\begin{array}{c}\text { Multivariate } \\
\text { analysis }\end{array}$ & \\
\hline \multirow[t]{4}{*}{ Surgical procedure } & E-E & $11 / 42$ & 1 & 1 & \\
\hline & SFA & $6 / 15$ & $1.49(0.55-4.04)$ & $0.91(0.32-2.64)$ & \\
\hline & EE-EA/REE-EA & $8 / 77$ & $0.41(0.16-1.02)$ & $0.35(0.14-0.87)$ & $p=0.025$ \\
\hline & Others & $4 / 14$ & $1.11(0.35-3.49)$ & $1.18(0.37-3.79)$ & \\
\hline \multirow[t]{2}{*}{ Associated defect } & Coarctation \pm VSD & $20 / 115$ & 1 & 1 & \\
\hline & Major defect & $9 / 33$ & $2.24(1.01-4.97)$ & $2.68(1.15-6.25)$ & \\
\hline \multirow[t]{2}{*}{ Resuscitation } & No & $24 / 129$ & 1 & 1 & \\
\hline & Yes & $5 / 19$ & $1.87(0.71-4.92)$ & $1.63(0.59-4.48)$ & \\
\hline \multirow[t]{2}{*}{ Age (days) } & $\geq 13$ & $7 / 73$ & 1 & 1 & \\
\hline & $\leq 12$ & $22 / 75$ & $3.32(1.42-7.79)$ & $3.54(1.44-8.70)$ & $p=0.006$ \\
\hline \multirow[t]{2}{*}{ Weight (kg) } & $\geq 3.4$ & $9 / 69$ & 1 & & \\
\hline & $\leq 3.3$ & $20 / 79$ & $2.26(1.03-4.98)$ & & \\
\hline \multirow[t]{3}{*}{ Arch anatomy } & Normal & $10 / 63$ & 1 & & \\
\hline & Hypoplasia isthmus & $9 / 37$ & $1.48(0.60-3.65)$ & & \\
\hline & Hypoplasia transverse arch & $10 / 48$ & $1.52(0.63-3.66)$ & & \\
\hline
\end{tabular}

See Table IV for abbreviations.

coarctation was influenced by the type of operation used, with the extended and radically extended end-to-end repairs achieving significantly better results than did the other procedures for anatomic arrangements involving hypoplasia of either the aortic isthmus or transverse arch. Third, the most important risk factor for the development of recoarctation was young age ( $<13$ days). Both the extended and radically extended procedures were associated with a significantly reduced risk of coarctation.

Before considering further the implications of these findings, we should examine certain limitations of the study. Two particular features will be discussed, beginning with the problems of what constitutes a hypoplastic aortic arch. ${ }^{18-20}$ The definition of hypoplastic aortic arch used in this study reflects the clinical practice during the study. The course of management chosen for each child was based on a qualitative assessment of perioperative investigations and the degree of hypoplasia at operation.

For this study we used a consistent definition of hypoplasia, and any unexpected weighting of the distri- 


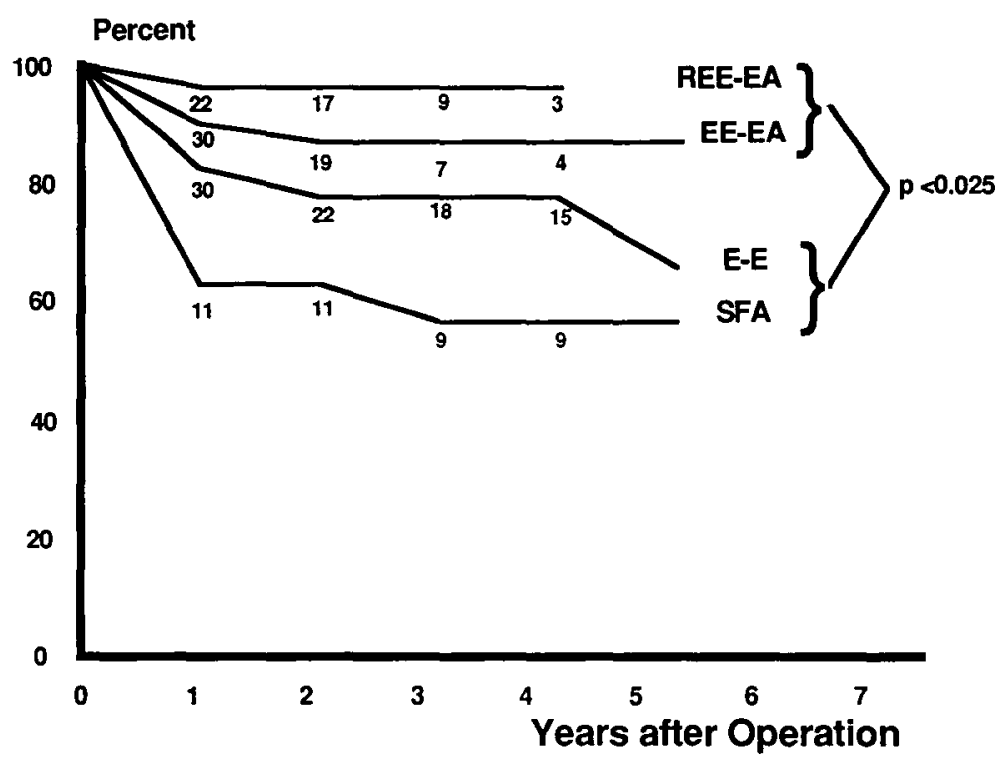

Fig. 5. Actuarial estimation of freedom from recoarctation after different surgical techniques. $R E E-E A$, Radically extended end-to-end anastomosis; $E E-E A$, extended end-to-end anastomosis into arch; $E$ - $E$, traditional end-to-end anastomosis; $S F A$, subclavian flap angioplasty.

bution of hypoplasia to any treatment group seems unlikely. Further, the prevalence of hypoplasia of the aortic arch in this series is broadly similar to that reported by others in similar patients. ${ }^{21}$

In view of the findings of the present study, it is pertinent to ask whether it is necessary to objectively define hypoplasia. Clearly, it is important in the extreme situations of aortic atresia and hypoplastic left heart syndrome, when decisions relating to the Norwood procedure or transplantation become necessary. However, our data suggest that the extended aortoplasties are successful for almost all anomalies of the arch. The second potential problem that might influence the interpretation of these data relates to the definition and diagnosis of recoarctation. Although $75 \%$ of patients had detailed Doppler studies at our institution, some had only clinical follow-up elsewhere.

We assumed that any patient who had normal femoral pulses with no radiofemoral delay or upper limb hypertension and who was also free of symptoms was highly unlikely to have recurrent coarctation. If an upper limb-to-lower limb systolic pressure gradient of less than $20 \mathrm{~mm} \mathrm{Hg}$ was detected on clinical blood pressure estimation, the patient was considered to have a recoarctation (for the purposes of this study). It was not considered ethical to subject these patients to cardiac catheterization. This policy might influence the data as follows: Because Doppler studies are more likely to overestimate than underestimate the gradient across a coarctation, a number of patients might have been included in the recoarc- tation group when, in fact, no recoarctation was present. The prevalence of residual coarctation might also be exaggerated by peripheral augmentation of the pulse because the pressure gradient was measured between the right arm and descending aorta; conversely, the clinical follow-up may have excluded some patients who did have a recoarctation within our definition. A neutral bias might thus be assumed.

The actuarial 5-year survival after operation in this series was $96 \%$ for simple coarctation and $90 \%$ for coarctation with isolated VSD. Lacour-Gayet, ${ }^{21} \mathrm{Ziemer}^{22}$ Harlan, ${ }^{23}$ and Trinquet ${ }^{24}$ and their associates reported actuarial survivals at 5 years after simple coarctation of $87 \%, 85.5 \%, 82 \%$, and $90 \%$, respectively. After repair of coarctation with VSD, their results were $88.5 \%, 80 \%$, $89 \%$, and $84 \%$. This series of patients contains a relatively larger percentage of infants ( $48 \%$ ) with simple coarctation than the other recently published series.

The risk of death after operation for simple coarctation is low, unless the child requires preoperative resuscitation for cardiac arrest. Therefore, it is vital that preoperative treatment at referring hospitals, during transit, and on arrival at the specialist institution be optimal. The appropriate use of prostaglandin $E_{1}$ is mandatory, and recent advances in both telephone diagnosis ${ }^{25}$ and the logistics of transporting sick babies might help to minimize the risks.

Our late results for operation of the combination of VSD and coarctation are less satisfactory; there were four late deaths. The mortality after operation for coarctation 
of the aorta associated with complex intracardiac anomalies was high. Eleven of 35 patients died in the hospital during admission for coarctation operation, and 7 died later, including 6 at the time of definitive repair. These data resulted in an actuarial survival of only $39 \%$ at 5 years (48\% at 1424 days). Although unsatisfactory, these results are not different from those presented in some other recent series. ${ }^{22,24}$ The relationship between diagnosis and death is shown in Table $\mathrm{I}$.

Most of the children who died did so within a year of coarctation repair. This high mortality can be explained partly by the prevalence of major cardiac malformations for which only palliative treatment is possible and a poor outcome is likely.

It is important to consider whether alternative management strategies might have produced more satisfactory results. A residual gradient of less than $20 \mathrm{~mm} \mathrm{Hg}$ after coarctation repair was associated with a significantly higher mortality in patients in group III when associated with a simultaneous pulmonary artery banding. Indeed, all the patients with this combination of pulmonary artery band and residual coarctation gradient of less than $20 \mathrm{~mm}$ $\mathrm{Hg}$ died within 1 year of operation. These patients were clearly subject to biventricular outflow tract obstructions with, presumably, adverse consequences for ventricular function. Five of the patients who died had atrioventricular septal defects and pulmonary artery banding, and three of these patients had Taussig-Bing anomalies, which were also banded. Successful one-stage repair of major congenital heart defects has been reported in many recent studies; operation on the aortic arch via an anterior approach during cardiopulmonary bypass has also been reported to have good results. ${ }^{26,28}$

Our data would support the use of single-stage primary repair of complex defects involving coarctation of the aorta and left-to-right shunts severe enough to otherwise warrant pulmonary artery banding. Such an approach has been advocated by others. ${ }^{29}$ An alternative strategy might be to persist with the plan of coarctation repair with simultaneous pulmonary artery banding and either immediately revise any operation that results in a gradient of less than $20 \mathrm{~mm} \mathrm{Hg}$ over the arch or redo the procedure as quickly as possible (certainly within 3 months if the cardiac anatomy permits).

A third approach to be considered would be to perform coarctation repair and to attempt definitive repair within a very short period of time without previous pulmonary artery banding. Trinquet and colleagues ${ }^{24}$ suggested that the presence of a hypoplastic aortic arch was a risk factor for early death after coarctation repair. This has not been borne out in our study; however, the choice of operative procedure for arch repair did influence the development of recoarctation, with the extended arch aortoplasties achieving significantly better results $(p=0.025)$ than did the other procedures used.

Radically extended arch aortoplasty was used almost exclusively in those patients in whom the surgeon judged the transverse arch hypoplasia to be important (i.e., in those patients with the "worst" aortic arches). Yet this procedure and its less radical counterpart resulted in the lowest recoarctation rate. Why should this be so? Residual coarctation can be caused by inadequate anastomotic size, by untreated proximal or distal hypoplasia, by lack of available tissue to perform an adequate repair, or, simply, by performing the operation badly. The extended arch aortoplasties address the majority of these factors because they result in long anastomoses, they treat proximal and distal hypoplasia, and we have never found they have never exhibited lack of tissue with this method in our experience.

Recurrent coarctation can be caused by either lack of growth of arch tissue on the anastomosis or ingrowth or contraction of ductal tissue. The ductal tissue distribution is well described and, if incompletely excised, might initiate recoarctation. ${ }^{31-34}$ The extended arch aortoplasties address these factors by providing a long anastomosis, excising ductal tissue, and dividing a residual ductal ring with an isthmic inlay flap. These operations thus combine the advantages of both the subclavian flap and the endto-end procedures. ${ }^{35-37}$ It has been suggested that the type of suture material used can influence outcome. ${ }^{10,23,31}$ In this study, however, there was no difference in the prevalence of recoarctation between the use of absorbable and nonabsorbable sutures. However, it is much more difficult to perform the radically extended end-to-end anastomosis procedure with PDS sutures, because the sutures do not pull through the tissues as easily as Prolene sutures (Ethicon) do when a number of loops of sutures have to be tightened. We would thus advise the use of 7-0 Prolene or Maxon sutures for this type of repair.

The prevalence of postoperative complications must also be taken into account when choosing a particular operation. Few centers, however, have reported morbidity data. Two patients in this series had Horner's syndrome after subclavian flap angioplasty. This complication has been described previously, ${ }^{40}$ having occurred after damage to the ansa cervicalis during extensive mobilization of the subclavian artery.

Subclavian flap angioplasty has also been suggested as a causative factor in the development of shortening and claudication of the left arm and in the development of the subclavian arterial steal syndrome. ${ }^{41,42} \mathrm{We}$ are also aware of patients from other institutions who have required amputation after subclavian flap angioplasty. However, the potential for neurologic damage is of greater concern. This is especially relevant in the radical- 
ly extended aortoplasty in which the left subclavian artery, left carotid artery, and a portion of the innominate artery are occluded by a vascular clamp. The operative technique we used involved the meticulous, continuous monitoring of arterial blood pressure in the right arm by direct cannulation together with, in most cases, the placement of a transcutaneous oxygen saturation probe on the fingers of the left hand. In practice we have used data only from the right arm pressure and wave form to influence the placement of and traction on our clamps. However, there is clearly no guarantee in any child that the circle of Willis will be able to provide collateral flow to the left brain or, via the vertebral artery, to the left arm. In our series, three of the four patients who had seizures after the operation had had extended arch aortoplasties; none had been resuscitated before the operation. In each of these patients, the seizure activity was very short-lived, and all patients had normal results from neurologic assessment and were receiving no relevant therapy at the time of this study.

Although these data suggest that extended aortoplasties of the arch are not associated with a long-term risk of brain damage, we retain a high level of awareness in the early and late follow-up of these patients. Lacour-Gayet and associates ${ }^{21}$ did not report any major neurologic complications of extended arch aortoplasty.

The data presented in this paper may be interpreted as providing strong support for the proposition that the extended end-to-end aortoplasties represent the treatment of choice for arch hypoplasia at the present time. The less radical extended procedure is also applicable, without technical modification, to simple coarctation because it avoids the need to sacrifice the left subclavian artery and appears to perform better in the medium term than do the other traditional repairs. The difference between the ordinary extended end-to-end aortoplasty and its more radical variant is simply in the degree of mobilization and the positioning of clamps. Thus, for simple coarctation, we advocate inclusion of the left carotid artery in the proximal clamp to permit the creation of a long anastomosis. There is another important but unquantifiable factor concerning the extended arch aortoplasty procedures that we wish to mention in this discussion. It is possible to thoroughly learn (and teach) one operative procedure that is capable of producing good results across almost the entire range of aortic arch anomalies, from simple coarctation to severe hypoplasia.

The data presented in this study suggest that the extended and radically extended arch aortoplasties had significantly better results in our experience than did either the traditional end-to-end repair or the subclavian flap angioplasty when used for repair of coarctation of the aorta and especially in the presence of hypoplasia. The performance was judged on postoperative gradient, recoarctation rate, and mortality. Patients in whom the arch is likely to be difficult to repair (very severe hypoplasia) and in whom a pulmonary artery banding would be required should be considered for primary definitive repair of both arch and intracardiac defects because the results of the conservative management described in this paper are so poor. In view of the superior performance of the extended arch aortoplasties in our hands, and because their principle can be applied to all arch anomalies, they have become our treatment of first choice in the management of coarctation of the aorta (with or without hypoplasia).

\section{REFERENCES}

1. Vouhé PR, Trinquet F, Lecompte $Y$, et al. Aortic coarctation with hypoplastic aortic arch: results of extended endto-end aortic arch anastomosis. J THORAC CARDIOVASC SURG 1988;96:557-63.

2. Baudet E, Al Qudah A. Late results of the subclavian flap repair of coarctation in infancy. J Cardiovasc Surg 1989; 30:445-9.

3. Pinzon JL, Burrows PE, Benson LN, et al. Repair of coarctation of the aorta in children: postoperative morphology. Radiology 1991;180:199-203.

4. Crafoord C, Nylin G. Congenital coarctation of the aorta and its surgical treatment. J THORAC SURG 1945;14:34761.

5. Gross RE, Hufnagel CA. Coarctation of the aorta: experimental studies regarding its surgical correction. N Engl J Med 1945;233:287-93.

6. Vossschulte K. Isthmusplastik zur Behandlung der Aortenisthmusstenose. Thoraxchirurgie 1957;4:443-50.

7. Waldhausen JA, Nahrwold DL. Repair of coarctation of the aorta with a subclavian flap. J THORAC CARDIovasC SURG 1966;51:532-3.

8. Hopkins RA, Kostic I, Armiru U, et al. Correction of coarctation of the aorta in neonates and young infants: an individualized surgical approach. Eur J Cardiovasc Surg 1988;2:296-304.

9. Zannini L, Lecompte $Y$, Galli R, et al. La coartazione aortica con ipoplasia dell'arco: descrizione di una nuova technica chirurgica. G Ital Cardiol 1985; 15:1045-8.

10. Lansman S, Shapiro AJ, Schiller MS, et al. Extended aortic arch anastomosis for repair of coarctation in infancy. Circulation 1986;74(Suppl):I37-41.

11. Amato JJ, Rheinlander HF, Cleveland RJ. A method of enlarging the distal transverse arch in infants with hypoplasia and coarctation of the aorta. Ann Thorac Surg 1977; 23:261-3.

12. Elliott MJ. Coarctation of the aorta with arch hypoplasia: improvements on a new technique. Ann Thorac Surg 1987;44:321-3.

13. Siewers RD, Ettedgui J, Pahl E, Tallman T, del Nido PJ. Coarctation and hypoplasia of the aortic arch: Will the arch grow? Ann Thorac Surg 1991;52:608-14.

14. Nadas AS, Fyler DC. Pediatric cardiology. Philadelphia: WB Saunders, 1972: 665. 
15. Walker SH, Duncan DB. Estimation of the probability of an event as a function of several independent variables. Biometrika 1967;54:167-79.

16. Cox DR. Regression models and life tables. J R Stat Soc 1972;34:187-220.

17. Kaplan EL, Meier P. Nonparametric estimation from incomplete observations. J Am Stat Assoc 1958;53:457-81.

18. Sinha SN, Kardatzke ML, Cole RB, Muster AJ, Wessel $\mathrm{HU}$, Paul MH. Coarctation of the aorta in infancy. Circulation 1969;40:385-98.

19. Moulaert AJ, Bruins CC, Oppenheimer-Dekker A. Anomalies of the aortic arch and ventricular septal defects. Circulation 1976;53:1011-5.

20. Pellegrino A, Deverall PB, Anderson RH, et al. Aortic coarctation in the first three months of life. an anatomopathological study with respect to treatment. J THORAC Cardiovasc Surg 1985;89:121-7.

21. Lacour-Gayet F, Bruniaux J, Serraf A, et al. Hypoplastic transverse arch and coarctation in neonates. Surgical reconstruction of the aortic arch: a study of sixty-six patients. J Thorac Cardiovasc Surg 1990;100:808-16.

22. Ziemer G, Jonas RA, Perry SB, Freed MD, Castaneda AR. Surgery for coarctation of the aorta in the neonate. Circulation 1986;74(Suppl):25-31.

23. Harlan JL, Doty DB, Brandt B, Ehrenhaft JL. Coarctation of the aorta in infants. J Thorac Cardiovasc Surg 1984;88:1012-9.

24. Trinquet F, Vouhé PR, Vernant F, et al. Coarctation of the aorta in infants: Which operation? Ann Thorac Surg 1988;45:186-91.

25. Franklin RC, Spiegelhalter DJ, Macartney FJ, Bull K. Evaluation of a diagnostic algorithm for heart disease in neonates. BMJ 1991;302:935-9.

26. Scott W, Rocchini AT, Bove EL, et al. Repair of interrupted arch in infancy. J THORAC CARDIOvaSC SURG 1988; 96:564-8.

27. Sell JE, Jonas RA, Mayer JE, Blackstone EH, Kirklin JW, Castaneda AR. The results of a surgical program for interrupted aortic arch. J THORAC CARDIOVASC SURG 1988; 96:864-77

28. Hazekamp MG, Quaegebeur JM, Singh S, et al. One stage repair of aortic arch anomalies and intracardiac defects. Eur J Cardiothorac Surg 1991;5:283-7.

29. Bergdahl LAL, Blackstone EH, Kirklin JW, Pacifico AD, Bargeron LM. Determinants of early success in repair of aortic coarctation in infants. J THORAC CARDIOVASC SURG 1982;83:736-42.

30. Sanchez GR, Balsara RK, Dunn JM, Mehta AV, O'Riordan AC. Recurrent obstruction after subclavian flap repair of coarctation of the aorta in infants: Can it be predicted or prevented? J ThORAC CardiovasC Surg 1986; 91:738-46.

31. Cobanoglu A, Teply JF, Grunkemeier GL, Sunderland $\mathrm{CO}$, Starr A. Coarctation of the aorta in patients younger than three months: a critique of the subclavian flap operation. J Thorac Cardiovasc Surg 1985;89:128-35.

32. Maehara T, de Leval M, Elliott MJ. Unusually early recoarctation after extended end-to-end anastomosis in a neonate. Ann Thorac Surg 1990;49:814-5.
33. Kopf GS, Hellenbrand W, Kleinman C, Lister G, Talner N, Laks H. Repair of aortic coarctation in the first three months of life: immediate and long-term results. Ann Thorac Surg 1986;41:425-30.

34. Beekman RH, Rocchini AP, Behrendt DM, et al. Longterm outcome after repair of coarctation in infancy: subclavian angioplasty does not reduce the need for reoperation. J Am Coll Cardiol 1986;8:1406-11.

35. Williams WG, Shindo G, Trusler GA, Dische MR, Olley PM. Results of repair of coarctation of the aorta during infancy. J Thorac Cardiovasc Surg 1980;79:603-8.

36. Sciolaro C, Copeland J, Cork R, Barkenbush M, Donnerstein R, Goldberg S. Long-term follow-up comparing subclavian flap angioplasty to resection with modified oblique end-to-end anastomosis. J THORAC CARDiovasc Surg 1991;101:1-13.

37. Moulton AL, Brenner JI, Roberts G, et al. Subclavian flap repair of coarctation of the aorta in neonates. Realization of growth potential? J THORAC CARDIOVASC SURG 1984; 87:220-35.

38. Ho SY, Anderson RH. Coarctation, tubular hypoplasia, and the ductus arteriosus: histological study of 35 specimens. Br Heart J 1979;41:268-74.

39. Russell GA, Berry PJ, Watterson K, Dhasmana JP, Wisheart JD. Patterns of ductal tissue in coarctation of the aorta in the first three months of life. $J$ THORAC CARDIOVASC SURG 1991;102:595-601.

40. Van Son JAM. Late circulatory results of surgical repair of coarctation of the aorta in infancy [Thesis]. Nijmegen: SSN, 1990:84.

41. Todd PJ, Dangerfield PH, Hamilton DI, Wilkinson JL. Late effects on the left upper limb of subclavian flap aortoplasty. J Thorac Cardiovasc Surg 1983;85:678-81.

42. Van Son JAM, Daniëls O, Vincent JG, Van Lier HJJ, Lacquet LK. Appraisal of resection and end-to-end anastomosis for repair of coarctation of the aorta in infancy: preference for resection. Ann Thorac Surg 1989;49:496502.

\section{Discussion}

Dr. Joseph J. Amato (New Hyde Park, N.Y.). I would have to disagree with the conclusions of this study. Although the authors conclude that extended end-to-end repair or radical end-to-end repair can be used for all repairs, the question still remains, should it be used?

In the September 1991 issue of the Annals of Thoracic Surgery, we presented a classification for coarctation of the aorta directed to the surgeon, which is as follows: Type I classification deals with primary coarctation with or without patent ductus arteriosus with no other major cardiac defects; this is an isolated juxtaductal coarctation that includes neither hypoplasia of the isthmus nor the arch. Type II deals with juxtaductal coarctation at the isthmus or hypoplasia of the isthmus that, however, does not extend into the arch. Type III includes coarctation with tubular hypoplasia involving the isthmus and the segment between the left carotid and subclavian arteries. There are subtypes to all these. Subtypes IA, IIA, and IIIA would include the presence of a VSD; subtypes IB, IIB, and IIIB would include other major cardiac defects. We agree that extended or radical repair could be used in all cases, but we also believe that the 
surgeon should not be prejudiced by a predetermined choice of optimal repair. If these classifications are followed, then the type I coarctation can be repaired with a simple end-to-end anastomosis. We might be dealing with semantics because the surgeon decides whether to extend the end-to-end anastomosis, perhaps slightly upward or downward. We believe that the type II condition with hypoplasia can be repaired with a subclavian flap operation. Type III can be treated with the extended repair that the authors suggest.

I have two questions to ask of the authors. Although you had no neurologic complications, what would happen to the child with an incomplete circle of Willis if you occlude the left carotid and the subclavian artery on one side? The second question relates to the statement that a questionnaire was sent out to your referring cardiologists. What value is attached to the responses of that questionnaire?

Dr. John L. Myers (Hershey, Pa.). We have had experience with approximately 75 patients with subclavian flap aortoplasty who were younger than 1 year of age; the reoperation rate was less than $10 \%$. We have seen patients who have had tubular hypoplasia or an aortic arch that is too small and required some form of augmentation at the time of coarctation repair. We have used the technique that you have described in approximately 20 patients with no deaths.

The question I have for you is this: On the basis of your data, do you now use the extended end-to-end repair for all patients with coarctation of the aorta?

Dr. John G. Coles (Toronto, Ontario, Canada). At the Hospital for Sick Children in Toronto we have used a strategically different approach to the management of aortic arch hypoplasia at the time of primary repair of coarctation. In the 10-year period ending December 1991, among 322 patients younger than 3 months of age with coarctation repair, primary repair of the aortic arch was elected in only $5 \%$ of the patients. We define arch repair as a technique in which the suture line extends proximal to the origin of the left subclavian artery. In this patient group, aortic arch hypoplasia was present in $25 \%$ of patients based on intraoperative measurements of the transverse aortic arch vis-à-vis the descending thoracic aorta. The 4-year rate of freedom from reintervention in the form of reoperation or balloon dilatation or both was $90 \%$. Multivariate risk factor analysis for the recurrence of the event found the morphologic variable and the procedural variable (aortic atresia and primary aortic arch repair at the first operation, respectively) to be associated with a higher risk of recurrence. Secondary reoperation on the aortic arch, as opposed to recoarctation repair, was required in only five patients. No deaths occurred.

From this experience we conclude that (1) a policy of highly selective arch repair, probably by avoiding a suture line in the narrow segment of the transverse aortic arch, yields a low rate of recurrence and mortality; (2) primary aortic arch repair may actually increase the risk of recurrence of aortic arch obstruction; and (3) secondary repair of neglected arch hypoplasia, if necessary, is a safe procedure.

The authors' manuscript indicates that the relative risk of early mortality associated with subclavian flap anomalies was lower in the subclavian flap group than in the radical and extended resection groups. Furthermore, the mean postoperative gradient was less than $15 \mathrm{~mm} \mathrm{Hg}$ in the subclavian flap group. With this in mind, I would like to ask the authors to comment on the results of a direct statistical comparison between the subclavian flap group and the extended resection groups, excluding the conventional end-to-end group because the results in this subgroup were poorer with regard to early mortality rate and the need for reintervention. Second, does the high risk of neurologic complications in babies requiring preoperative resuscitation in any circumstances dissuade the authors from using this radical approach, given that it involves temporary occlusion of at least two of the arch vessels? Finally, please comment on the morphologic basis for recurrence, stratified according to the type of operation; in our experience, recurrence as a result of aortic arch hypoplasia per se was unusual.

Dr. van Heurn. Dr. Amato, our technique is easy to learn and may be used for both simple coarctation and associated hypoplasia of the arch and hypoplasia of the isthmus. There is only one technique to learn. It can be applied to almost every arch, and we have shown that the recoarctation rate is significantly lower than that for other procedures. We think this may be true because there is an isthmic inlay flap that divides a possible ring of microscopic ductal tissue, which may be left after operation. Last year in this JouRNAL (1991;102:596-601), a study from Bristol, England, showed that there were often remnants of ductal tissue, especially a tongue of ductal tissue opposite to the duct. With this incision and the isthmic inlay flap, we hope that we can prevent recoarctation; thus, even in simple coarctation without arch hypoplasia, an extended end-to-end repair may be better.

We are well aware that it is possible to have neurologic complications after clamping all these vessels, but we have not yet seen such complications, and we hope we will not see them at all. We have reviewed the literature, and Lacour-Gayet and associates, ${ }^{21}$ using the same technique, reported a large series with no neurologic complications.

Regarding the value of the questionnaire, about $80 \%$ of all patients were followed up at Great Ormond Street, and then detailed questionnaires were sent to cardiologists and general practioners. If we didn't receive adequate answers from cardiologists, we contacted them personally. Patients were called back if adequate answers to our questions were not available. Therefore we think our data are accurate.

Dr. Myers, with regard to subclavian flap angioplasty, we suggest, as I have said earlier, that the extended end-to-end repair may be the operation of choice in simple coarctation as well. It combines the advantages of the traditional end-to-end repair and subclavian flap angioplasty. The technique incorporates an inlay flap as in the subclavian flap angioplasty, and "excised" microscopic ductal tissue as in the normal end-to-end repair. Another advantage is that the subclavian artery is preserved. Although complications resulting from tying a subclavian artery are not frequent, they do exist. We think it is preferable to avoid tying the subclavian artery.

Dr. Coles, some patients in our study we did not undergo reoperation or angioplasty. This was necessary in only $25 \%$ of patients. Gradients after different procedures were lower with the extended end-to-end repair and radically extended end-toend repair. If there was a simple coarctation without arch hypoplasia, subclavian flap angioplasty achieved results comparable with those of traditional, extended, and radically extended end-to-end repair. No difference in gradient existed for simple coarctations without arch hypoplasia, although a difference in recurrent coarctation did exist. Extended and radically extended end-to-end repair and subclavian flap angioplasty had the same early mortality (7\%). The traditional end-to-end repair showed a slightly higher mortality, but this was not significant.

I have answered the neurologic question, and we hope we will not see any neurologic complications after this operation. 